\title{
Weather and Child Health in Rural Nigeria
}

\author{
Mariano Rabassaa , Emmanuel Skoufias ${ }^{b, *}$ and Hanan Jacoby ${ }^{c}$

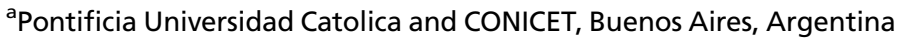 \\ ${ }^{\mathrm{b}}$ The World Bank, $1818 \mathrm{H}$ Street NW, Washington, DC, USA \\ 'Research Department, The World Bank, Washington, DC, USA \\ * Corresponding author: Emmanuel Skoufias. E-mail: eskoufias@worldbank.org
}

\begin{abstract}
The effect of weather shocks on children's anthropometrics is investigated using the two most recent rounds of the Nigeria Demographic and Health Survey (DHS). For this purpose, climate data for each DHS cluster are interpolated using daily weather station records from the national network. The findings reveal that rainfall shocks have a statistically significant and robust impact on child health in the short-run for both weight-for-height and height-for-age, and the incidence of diarrhoea. The impacts of weather shocks on health are of considerable magnitude; however, children seem to catch-up with their cohort rapidly after experiencing a shock. Finally, it appears that the impact of these shocks is the same for young boys and girls, which suggests that there is no gender-based discrimination in the allocation of resources within households.
\end{abstract}

JEL Classification: I12, J16, 015

\section{Introduction}

There is an increasing recognition that the inability of poor households to insure effectively against risk, especially in the rural areas of developing countries, is likely to result in costly ex post consumption-smoothing strategies, such as liquidating productive assets or drawing down investments in response to bad shocks (Dercon, 2002). Of primary concern is the extent to

(C) The Author 2014. Published by Oxford University Press on behalf of the Centre for the Study of African Economies. All rights reserved. For permissions, please email: journals. permissions@oup.com 
which the income volatility due to weather fluctuations faced by households in agriculture has a negative impact on investments in the human capital of children, especially if such investments have long-run effects that affect their well-being later in life (Alderman et al., 2006; Currie, 2009; Dercon and Porter, 2010).

Evidence from Jacoby and Skoufias (1997) that parents in rural India withdraw children from school in response to negative income shocks induced by poor rainfall indicates a significant downside to self-insurance, one borne largely by the subsequent generation. ${ }^{1}$ Yet, without follow-up information on the eventual schooling (or labour market) outcomes of these children it is difficult to evaluate the long-run cost of this particular consumptionsmoothing mechanism. More recently, Maccini and Yang (2009) find that rural Indonesian girls exposed to excess rainfall in their first year of life (though not in their second or subsequent years) grew up to become taller and better educated than their otherwise identical peers. While suggestive, this evidence linking uninsured income volatility and eventual human capital is indirect.

This paper looks to strengthen the linkage by considering the impact of rainfall shocks on child anthropometrics using the two most recent rounds of the Nigeria Demographic and Health Survey (DHS). One advantage offered by the DHS is that it provides information on infant and child health status accompanied by geographic coordinates of the cluster in which they reside. This allows us to interpolate rainfall data for each DHS cluster using daily weather station records from the national network of about 30 rainfall stations. Specifically, we analyse the impact of rainfall shocks on two anthropometric measures which capture two different dimensions of health status. We first look at weight-for-height, which is a summary measure of current nutritional status or health investment flow (Falkner and Tanner, 1986). In addition, we use height-for-age which better captures longer-term nutritional status or health stock. In the case of short-run impacts, we also analyse the effect that precipitation has on the incidence of child diarrhoea. Diarrhoea is a particularly important disease to study in this context because of its sensitivity to climatic conditions.

Like Maccini and Yang (2009), we exploit the fact that height is a cumulative measure of past health and nutrition shocks and should therefore reflect income variability experienced earlier in life. In our case, however, we

${ }^{1}$ Jensen (2000) provides similar evidence for child health investments in Africa. Alderman et al. (2006), Foster (1995) and Hoddinott and Kinsey (2001) also examine the child health effects of different types of weather shocks. 
examine height-for-age of children no more than five years of age, rather than of adults. The biomedical literature suggests that stature in adulthood is largely predetermined by age three (e.g. Martorell et al., 1994). A large body of evidence from developing countries also shows a causal link between malnutrition, as proxied by height, and success in school (see Glewwe and Miguel, 2008, for a review) and in the labour market (Strauss and Thomas, 1998). In short, child height-for-age is a good indicator of adult human capital. But what sets our approach apart is that we analyse a long-term measure of nutritional status (height-for-age) in combination with a short-term measure (weight-for-height) for the same sample of children.

Two additional features help distinguish this paper from existing research. First, it provides useful evidence on the impacts of rainfall shocks on child health in a country where this issue is understudied. The link between weather shocks and child health has received little attention in the empirical literature in general, although in recent years there have been substantial advances in our understanding of the complex interrelationships involved. Much of the existing literature for developing countries has focused on a rather extreme health outcome, child mortality. ${ }^{2}$ Given that vastly more children survive into adulthood than die, however, a greater focus on survivors' human capital seems warranted. Even fewer papers have analysed the impact of weather variability on child morbidity (Bandyopadhyay, Kanji and Wang, 2012), or have used anthropometric measures as a proxy for children's health status (Hoddinott and Kinsey, 2001; Bengtsson, 2010; Portner, 2010; Skoufias and Vinha, 2012).

Second, it sheds light on the channels through which rainfall related shocks affect child health. Like school attendance in Jacoby and Skoufias (1997), a child's weight-for-height should be sensitive to the current economic conditions of the household (see also Foster, 1995). This insight along with a key observation about the timing of rainfall shocks allows us to extract compelling evidence of an income effect from anthropometric data. The dependence of agriculture on rainfall and the ensuing seasonality of agricultural production in Nigeria (Odekunle, 2004) means that the effect of a rainfall shock during the growing season on income from farming in our setting takes place with a lag; that is, income is realised only after the crops have been harvested and, possibly, sold. The influence of rainfall on disease environment, by contrast, is largely contemporaneous. Excessive rainfall in poor countries

${ }^{2}$ Examples of such studies include Rose (1999), Kudamatsu et al. (2012) and Baird et al. (2010) among others. 
is linked to a higher incidence of diarrhoeal disease and, indirectly, to an increase in vector-borne diseases. Episodes of acute illness induced by high rainfall can lower a child's capacity to take in and retain essential nutrients from food. Thus, weight changes observed around the time of a monsoon rainfall shock but before the associated harvest should mainly reflect the change in disease environment, whereas weight changes observed postharvest should reflect the combined effects of income and the lagged effects of the disease environment that prevailed during the most recent monsoon. Finally, our analysis also addresses the question of whether households prioritise boys' welfare over that of girls during times of economic hardship. ${ }^{3}$

We find that a $10 \%$ increase in contemporaneous rainfall from historic norms shock leads to a reduction in the weight-for-height Z-score (WHZ-score) by 0.034 to 0.036 standard deviations, on average, i.e., $17 \%$ of the median Z-score in our sample of all children between 0 and 35 months of age. In contrast, a 10\% increase in rainfall in the last completed rainy season before the survey leads to an increase in the WHZ-score by 0.087 standard deviations. Thus, the positive 'income effect' of higher rains during the last agricultural season is larger than the negative 'disease environment effect'. We also find that the impacts of weather shocks (both rainfall and temperature) do not differ based on the gender of a child and that these impacts are transitory [it is only the shock from the most recent growing season that matters for height-for-age Z-scores (HAZ)]. The shortlived nature of past weather shocks suggests that children who have experienced a shock can rapidly catch-up with their nigerian cohort. Overall, our findings are in line with some results reported in the epidemiologic literature, but seem to contradict Maccini and Yang (2009) who report that shocks during the first 12 months since birth have a long-run effect on socioeconomic outcomes of Indonesian women (and not men) as adults.

The rest of the paper is organised as follows. Section 2 lays out the conceptual framework. Section 3 describes the anthropometric and rainfall data. Sections 4 and 5 present the empirical specification and estimation results, respectively. The final section recaps and discusses implications for policy.

${ }^{3}$ Dreze and Sen (1989) provide an early review of this literature in the South Asian context. Among many studies, Behrman and Deolalikar $(1988,1990)$ show biases in favour of boys in nutrient allocation among Indian households during lean times. Also in India, Rose (1999) shows that the gender bias in infant mortality, which normally favours boys, narrows when districts experience higher rainfall. 


\section{Conceptual framework}

A standard human capital production function specifies a child's nutritional status at the end of period $t\left(H_{t}\right)$ as a function $f$ of her nutritional status at the end of the previous period $\left(H_{t-1}\right)$, all of the relevant nutritional and health inputs she received during period $t\left(I_{t}\right)$, and her period $t$ disease exposure $\left(E_{t}\right)$. Thus,

$$
H_{t}=f\left(H_{t-1}, I_{t}, E_{t}\right),
$$

where lagged nutritional status captures the entire history of inputs and disease prior to period $t$ as well as the child's genetic endowments. Parental investment in child nutritional status consists principally in allocating caloric intake and other dimensions of food consumption, as well as in responding to illness induced by the disease environment, for instance by administering oral rehydration therapy during spells of diarrhoea.

Within this framework, there are two main channels through which excess rainfall can influence child nutritional status. The first is through the alteration of the disease environment net of any parental responses to child illness. In particular, flooding is associated with a higher contemporaneous incidence of diarrhoeal disease, most seriously typhoid and cholera (World Health Organization, 2002; Confalonieri et al., 2007). Standing water also indirectly leads to an increase in vector-borne diseases, such as malaria and dengue, through the expansion in the number and range of vector habitats. Such illnesses lower the capacity to take in and retain essential nutrients from food. Insofar as parents cannot entirely prevent or perfectly ameliorate these effects of child illness, excess rainfall shocks will have a negative impact on nutritional status through the disease channel.

The second main channel is through food consumption or real income. In a rural economy based largely on rain-fed agriculture, household income is of course highly dependent on rainfall realisations. Moreover, credit constraints limit households' ability to smooth consumption over time, rendering health more vulnerable to economic shocks (Behrman and Deolalikar, 1988, 1990; Foster, 1995). Finally, insofar as households are spatially dispersed and transport infrastructure is weak, markets in food staples may not be well integrated. Localised rainfall shocks may, consequently, influence food prices. When seasonal rains are plentiful, yields will be high, food supplies robust and prices low. Such general equilibrium effects reinforce the positive association between rainfall and household purchasing power or real income. Given the seasonal nature of agricultural production and limited borrowing opportunities, the effect from income to 
consumption, and thereby to child nutrition, is likely to take place with some delay; higher rainfall during the current cropping season can increase consumption only after harvesting.

A natural question to ask is whether it is possible to distinguish these disease environment and income channels empirically. Consider a child observed (weighed) during the current rainy season. Excess rainfall around this time (a current rainfall shock in our parlance) captures the disease environment effect, which, according to the discussion above, is likely to reduce the child's weight-for-height. At this point in the agricultural calendar, however, the household cannot yet avail itself of the increased purchasing power induced by the higher than normal rainfall; this windfall is realised only after the harvest, which has yet to take place. Hence, the income effect of a contemporaneous rainfall shock on the child's weight is essentially zero. ${ }^{4}$

In contrast, excess rainfall during the most recently completed growing season is likely to operate through both the income and disease environment channels. High past monsoon rainfall has a negative impact on previous period nutritional status through $E_{t-1}$, which is then carried through to the current period by $H_{t-1}$ in Equation (1). Moreover, plentiful rainfall during the last monsoon results in a better harvest, increasing $I_{t}{ }^{5}$ In sum, the reduced form impact of excess rainfall during the most recently completed growing season on child weight-for-height consists of two opposing effects: a (negative) lagged disease environment effect and a (positive) income effect; the reduced form impact is thus a lower bound on the income effect of rainfall shocks on child weight. Indeed, in principle, the reduced form effect of excess rainfall in the most recently completed growing season can be negative.

${ }^{4}$ Excess precipitation could have a contemporaneous effect on household income via changes in the local agricultural labour market. In particular, if the rainfall shock is realized prior to planting and there is significant scope to increase the area planted or the use of inputs that require a lot of labour to apply, then wages paid to hired farm workers may rise. We suspect, however, that such effects are of second-order importance at best in the context of rural Nigeria.

${ }^{5}$ To reiterate, it is not necessary to be a food producer in order to reap the benefits of higher yields if food markets are not perfectly integrated. In addition, rural households engaged in non-farm activities may experience an increase in demand, and hence income, when local agriculture is doing well. 


\section{Data and descriptive statistics}

\subsection{Demographic and health survey}

The data on child health comes from two rounds of the DHS conducted in 2003 and 2008. DHS is a nationally representative household survey with a large sample size containing detailed information on demographic characteristics and health status of both mothers and young children. ${ }^{6}$

Nutritional status, especially in young children, has been widely and successfully assessed by anthropometric measures in both developing and developed countries (Mei and Grummer-Strawn, 2007). Thus, following the norm in the literature we proxy the health status of children with their anthropometric measures and information on recent symptoms of illness, specifically diarrhoea. Children height and weight are converted into standardised Z-scores (height-for-age and weight-for-height), using the WHO Anthro program (World Health Organization Multicentre Growth Reference Study Group, 2006). For each child, depending on their sex and age, the $\mathrm{Z}$-score system expresses anthropometric values in terms of standard deviations below or above the median of an international reference group. ${ }^{7}$

The Nigeria DHS samples were selected using a stratified two-stage cluster design. The 2003 DHS consists of 7,864 households in 365 clusters or villages, with $54 \%$ of them being rural villages. In contrast, the 2008 DHS had a much larger sample size comprising 36,800 household in 886 clusters, $69 \%$ in rural areas. ${ }^{8}$ We restrict the sample to those born outside of urban areas because our causal factor of interest, rainfall variability, should mainly have an effect in agricultural areas. The locations of rural clusters from each round are displayed in Figure 1. The surveys are based on interviews to women of

6 There have been some concerns about the quality of household surveys in Nigeria. However, we expect that a standardized survey like the DHS, which has been used in many countries (including two previous rounds in Nigeria), would have reasonable quality controls. In fact, the DHS quality is such that it has been widely used to perform indirect estimation of population dynamics, such as fertility and mortality, in those places where there are no reliable census data.

${ }^{7}$ An international reference is useful since growth in height and weight of wellfed, healthy children under 5 years of age from different ethnic backgrounds and different continents is reasonably similar (World Health Organization Multicentre Growth Reference Study Group, 2006).

8 The 2003 DHS used the 1991 census frame while the 2008 DHS used the 2006 census frame. There is no available information regarding the definition of a rural area in the 2006 census frame. Some observers have suggested that the two frames might have used a different classification of EAs as rural or urban. However, our results are not qualitatively different if we only use the (larger) 2008 DHS. 


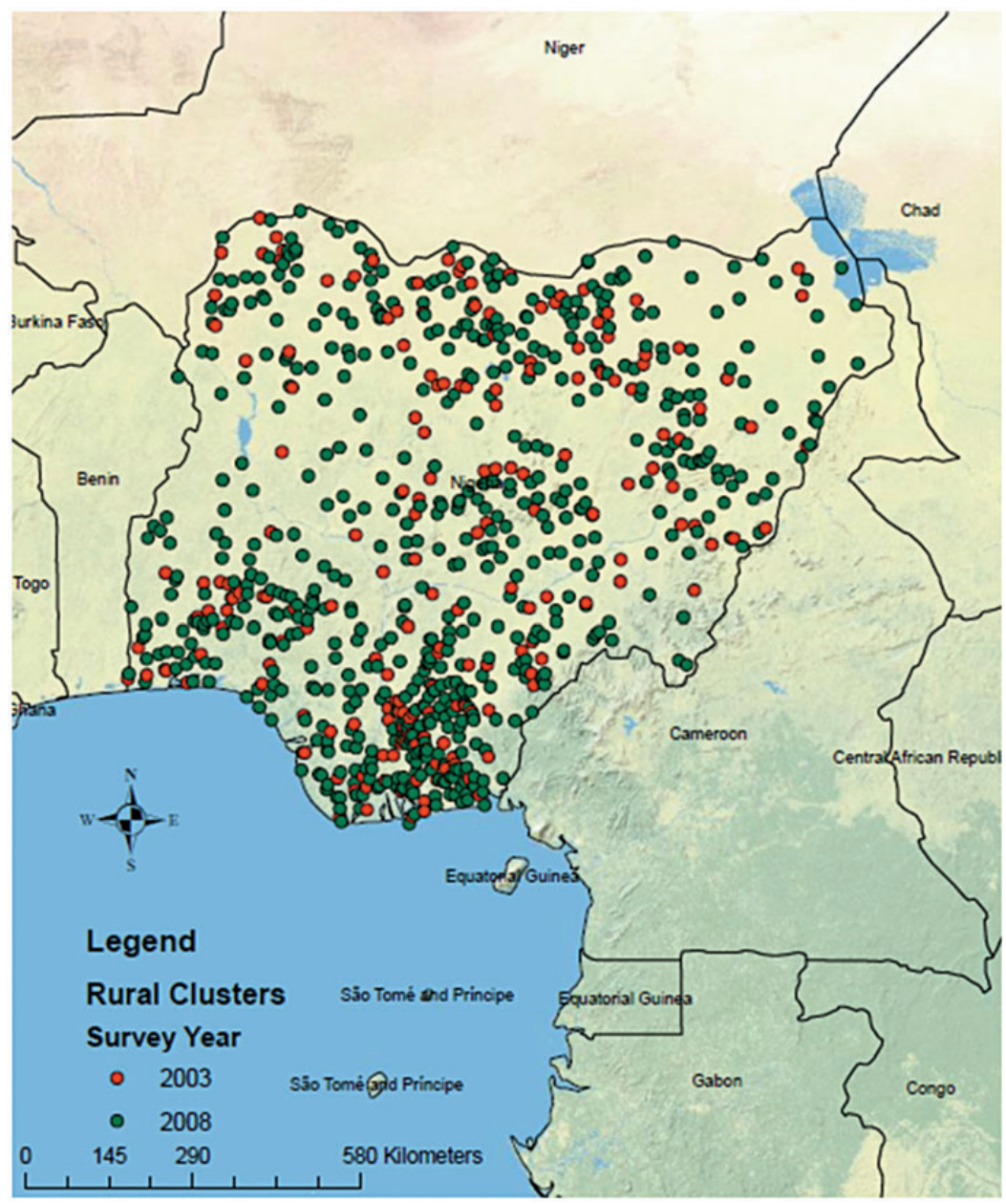

Figure 1: Location of Rural DHS Clusters by Survey Round.

childbearing age, i.e., between 15 and 49 years old, who were either permanent residents of the household or visitors present in the household on the night before the survey took place. We pool the two waves together to create a sample of about 11,500 child-level records that include birth dates and detailed child health characteristics.

We have decided to focus on the younger children (i.e., those between 0 and 35 months of age) for several reasons. First, young children are believed to be especially vulnerable to shocks that lead to growth faltering. Second, body size at adulthood is strongly correlated with stature at the age of 3 , 
and after this age children from even very poor localities will grow as quickly as children in developed economies. In turn, adult height is correlated with earnings and productivity, poorer cognitive outcomes and premature mortality due to increased risk of cardiovascular and obstructive lung disease (Hoddinott and Kinsey, 2001). In addition, children experiencing slow height growth usually perform less well in school, score poorly on the test of cognitive function, have lower activity levels and fail to acquire skills at normal rates. Finally, the evidence suggests that the period since birth to the age of 3 is the most critical period for the development of the immune system.

We removed biologically implausible values (most likely as the result of errors in measurement or data entry), using the cut-offs recommended by the WHO. Thus, data were excluded if a child's HAZ was below -6 or above +6 ( $12 \%$ of the observations), or WHZ was below -5 or above +5 standard deviations ( $10 \%$ of the sample). Our final sample has about 10,000 children at the age of $0-35$ months living in rural areas. ${ }^{9}$

The summary statistics can be compared with the international reference group, which has an expected mean Z-score of 0 for all normalised growth indices. In general, $Z$-scores 2 standard deviations below the reference are associated with severe growth retardation in the case of HAZ, and acute malnutrition for WHZ. The distributions of HAZ and WHZ for children $<36$ months of age of both rounds of the Nigeria DHS are displayed in Figure 2. The distribution of HAZ-scores is highly skewed to the left implying that growth retardation is very prevalent among young children of rural areas. The average child is 1.5 standard deviations shorter than the international reference mean, with almost $45 \%$ of children being stunted, i.e., their HAZ scores are under 2 standard deviations from the WHO median. ${ }^{10}$ Boys are more likely to suffer from growth retardation than girls. Regional differences are also significant. While more than half of the

9 Almost half of the improbable WHZ scores correspond to extremely high values, with a mean score of 10.4 and a median score of 8 . In contrast, the immense majority of dubious HAZ scores are at the low end of the distribution. We attempted to estimate the probability of having implausible Z-scores based on observable child, maternal and household characteristics, along with normal precipitation levels in the DHS cluster, the accessibility to health facilities and fixed effects for month of birth, month $\times$ year of interview and state of residence. Except from sex-females being less likely to report implausible Z-scores-none of the other characteristics systematically affects the estimated probabilities.

10 To have a sense of the magnitude of these figures, for a 3 -year-old child a 1 standard deviation would be equal to approximately $3.75 \mathrm{~cm}$ difference in height. 
(a)

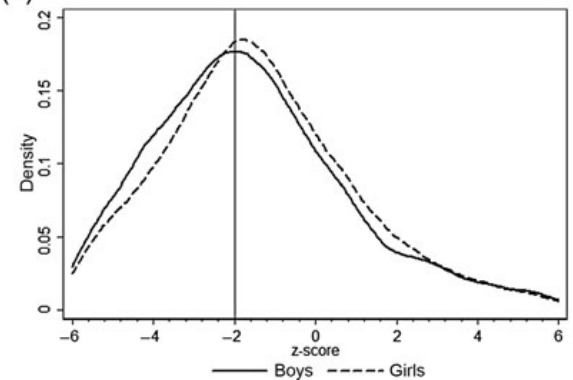

(b)

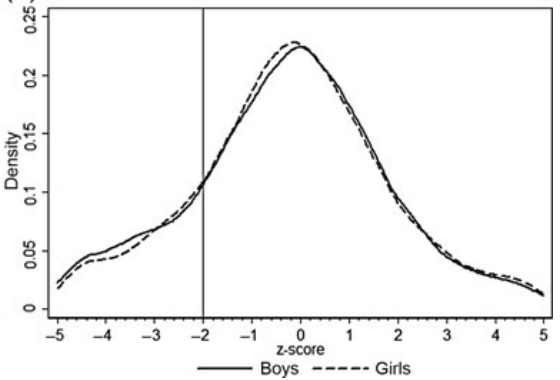

Figure 2: Z-scores for Children in Rural Areas. (a) Height-for-Age (b) Weight-for-Height

children in the northern part of the country are stunted; only $34 \%$ of children suffer from acute growth retardation in the southern regions (see Table 1 for more details).

Children also scored below the international mean for WHZ, although the mode of the distribution is closer to the international standard. Acute malnutrition affects $17 \%$ of children, with no discernible difference between boys and girls. Differences in WHZ-scores are also observed between the northern, central and southern regions of Nigeria (see right panel of Table 1 ). While $11 \%$ of children are wasted in the relatively rich southern region, almost a quarter of them suffer acute malnutrition in the north.

\subsection{Climate and weather data}

In the most recent DHS surveys, the location of sampled communities is geo-referenced using GPS technology. ${ }^{11}$ These data allow us to construct a precise history of climate for each DHS cluster. For this purpose, we combine the geographic location of clusters with detailed weather data from a large weather station network spanning from the mid-1980s to 2008 , the year of the last DHS. The geographic coverage of the network is fairly good except for the central east and central west parts of the country.

Rainfall is the most important dimension of weather variation in Nigeria. Because of its tropical location, temperature shows very little variation, either within years or across them. As noted by Nieuwolt (cited in Odekunle, 2004),

${ }^{11}$ However, in order to maintain confidentiality of respondents, the DHS randomly displaces the GPS coordinates of each cluster. Rural clusters contain a minimum of 0 and a maximum of $5 \mathrm{~km}$ of positional error (ICF Macro, 2011). Thus, even if the same clusters are sampled in two different rounds it would be impossible to identify them because they would have different geo-coordinates. 
Table 1: Descriptive Statistics for Z-scores

\begin{tabular}{|c|c|c|c|c|c|c|c|c|c|c|c|c|}
\hline \multirow[t]{3}{*}{ Regions } & \multicolumn{6}{|c|}{ Height-for-age } & \multicolumn{6}{|c|}{ Weight-for-height } \\
\hline & \multicolumn{3}{|l|}{ Gender } & \multicolumn{3}{|c|}{ Age in months } & \multicolumn{3}{|l|}{ Gender } & \multicolumn{3}{|c|}{ Age in months } \\
\hline & All & Boys & Girls & $0-11$ & $12-23$ & $24-35$ & All & Boys & Girls & $0-11$ & $12-23$ & $24-35$ \\
\hline \multicolumn{13}{|l|}{ All } \\
\hline Mean & -1.50 & -1.63 & -1.39 & -0.78 & -1.90 & -2.00 & -0.235 & -0.256 & -0.214 & -0.232 & -0.324 & -0.141 \\
\hline Standard deviations & $(2.350)$ & $(2.370)$ & $(2.323)$ & $(2.342)$ & $(2.280)$ & (2.198) & $(1.950)$ & $(1.967)$ & $(1.934)$ & $(2.101)$ & $(1.908)$ & (1.796) \\
\hline$\leq-2(\%)$ & 44.20 & 47.08 & 41.40 & 29.64 & 52.74 & 53.38 & 17.31 & 17.77 & 16.85 & 19.88 & 17.53 & 13.91 \\
\hline obs & 10,789 & 5,323 & 5,466 & 4,076 & 3,470 & 3,243 & 10,689 & 5,266 & 5,423 & 3,934 & 3,542 & 3,213 \\
\hline \multicolumn{13}{|l|}{ North } \\
\hline Mean & -1.73 & -1.82 & -1.63 & -0.81 & -2.27 & -2.34 & -0.557 & -0.643 & -0.474 & -0.487 & -0.647 & -0.546 \\
\hline Standard deviations & $(2.543)$ & (2.564) & (2.519) & (2.503) & $(2.410)$ & $(2.376)$ & $(2.122)$ & $(2.151)$ & $(2.093)$ & $(2.215)$ & $(2.119)$ & (1.997) \\
\hline$\leq-2(\%)$ & 51.07 & 52.75 & 49.44 & 32.90 & 62.45 & 62.55 & 25.14 & 26.61 & 23.71 & 26.10 & 26.10 & 22.81 \\
\hline obs & 4,756 & 2,343 & 2,413 & 1,836 & 1,518 & 1,402 & 4,749 & 2,345 & 2,404 & 1,793 & 1,575 & 1,381 \\
\hline \multicolumn{13}{|l|}{ Central } \\
\hline Mean & -1.57 & -1.74 & -1.40 & -0.88 & -1.94 & -1.99 & 0.051 & 0.072 & 0.031 & 0.050 & -0.056 & 0.169 \\
\hline Standard deviations & $(2.210)$ & (2.229) & $(2.180)$ & (2.263) & (2.088) & (2.071) & (1.806) & (1.809) & $(1.804)$ & $(2.0251)$ & $(1.690)$ & $(1.651)$ \\
\hline$\leq-2(\%)$ & 43.89 & 49.02 & 39.04 & 29.84 & 51.45 & 52.60 & 11.28 & 11.59 & 10.99 & 14.09 & 10.60 & 8.81 \\
\hline obs & 2,948 & 1,434 & 1,514 & 1,079 & 964 & 905 & 2,907 & 1,415 & 1,492 & 1,029 & 981 & 897 \\
\hline \multicolumn{13}{|l|}{ South } \\
\hline Mean & -1.10 & -1.22 & -0.98 & -0.63 & -1.28 & -1.51 & -0.004 & 0.037 & -0.045 & -0.082 & -0.073 & 0.160 \\
\hline Standard deviations & (2.104) & (2.130) & (2.071) & (2.138) & (2.119) & (1.926) & (1.715) & (1.682) & $(1.745)$ & $(1.927)$ & (1.666) & (1.469) \\
\hline$\leq-2(\%)$ & 33.91 & 36.68 & 31.12 & 24.29 & 39.07 & 40.38 & 10.81 & 9.83 & 11.79 & 15.20 & 10.75 & 5.67 \\
\hline obs & 3,085 & 1,546 & 1,539 & 1,161 & 988 & 936 & 3,033 & 1,506 & 1,527 & 1,112 & 986 & 935 \\
\hline
\end{tabular}

Notes: Based on children 0-35 months of age from the 2003 and 2008 DHS rural clusters. States are grouped into agroclimatic regions as north: Kebbi, Sokoto, Zamfara, Katsina, Kano, Jigawa, Bauchi, Yobe, Gombe, Borno and Adamawa; central: Kwara, Niger, Kogi, FCT Abuja, Kaduna, Nassarawa, Plateau, Benue and Taraba and south: Lagos, Ogun, Oyo, Osun, Ondo, Ekiti, Edo, Delta, Anambra, Imo, Enugu, Ebonyi, Cross River, Abia, Bayesla, Rivers and Akwa Ibom. 
temperatures are not a critical factor in tropical agriculture. Therefore, in this study we focus on the effects of precipitation shocks.

One of the key aspects of this study is to give proper weight to climate interpolations. Although many studies have linked health outcomes with climate, an inadequate match may lead to serious biases. Thus, we carefully interpolate climate and weather data from the network of stations to the precise location of each DHS cluster. The usual practice in the economic literature is to match each locality - a cluster or the geographic centre of an administrative unit-to the geographically closest weather station (for examples, see Yang and Choi, 2007; Maccini and Yang, 2009). While simple, this interpolation method may yield poor results if missing records are prevalent in the weather data, stations have been affected by site relocation, or considerable differences exist in terms of topographic characteristics, for example, altitude, between the location of the cluster and the location of the closest station. The replacement of missing data with data from the second closest weather station will introduce artificial variation in weather, whereas the differences in topography will introduce a bias in the interpolated values.

Another alternative is to predict climate using statistical methods, similar to those used in climate modelling (for an application in the economic literature see Nordhaus et al., 1994). This approach requires estimating climate (or weather) based on stations' observable characteristics such as latitude, longitude, altitude, distance to the sea and agroclimatic zones, and then using the regression coefficients to predict the corresponding values to each DHS cluster. We have opted for this approach because it better fits the observed climate at the weather station site. ${ }^{12}$

In order to assess the effect of rainfall shocks on children's health, we examine the deviations with respect to the normal rainfall during the agricultural growing season. The growing season is usually defined as the period of the year during which rainfall distribution characteristics are suitable for crop germination, establishment and full development. Such a period would not exhibit significant variation from year to year. However, the empirical identification of the length of the growing season is in itself challenging because rainfall in Nigeria has considerable spatial variability: from a tropical climate

12 Alternatively, one might use climate and weather data from general circulation models (GCM). These global climate models use much more complex methods to interpolate observed climate at weather stations into spatial grids, which in turn can be used to interpolate climate at the sampled cluster. While GCM might capture better complex atmospherically process their primarily objective is not to represent weather conditions at a fine spatial resolution. Therefore, the coarse spatial nature of these models would generate much less spatial variability in our main variables of interest. 
in the south to a semi-arid climate in the Sahel. Therefore, to account for this variability we divide the country in three distinct zones using the estimates of the length of the growing season presented in Odekunle (2004). ${ }^{13}$ The resulting mean lengths are approximately 6 months in the south (from early May to the end of October), 4 months in the central part of the country (from June to September) and only 2 months in the north (from July to August). Table 2 presents summary statistics of rainfall deviations from normal. ${ }^{14}$

As opposed to rainfall patterns, normal temperatures are relatively uniform and the seasonal variation is small, thereby allowing a wide range of suitable crops in relation to temperature conditions. This happens especially in the central-south parts of the country where the mean monthly longterm temperature fluctuates between 25 and $30^{\circ} \mathrm{C}$. The period between February and April is the hottest during the year; a period corresponding to the dry season. Northern Nigeria presents more variability in terms of temperature which ranges between 22 and $33^{\circ} \mathrm{C}$.

\section{Identification strategy}

In this section, we present the reduced form equations for the analysis. As mentioned above, we rely on two anthropometric measures that capture two different dimensions of health: weight-for-height and height-for-age. ${ }^{15}$

\subsection{Weight-for-height}

The WHZ-scores are a good indicator of short-term health status for young children. We estimate the following reduced form equation for children aged

13 Specifically, Odekunle (2004) used 40 years of daily rainfall data from five weather stations (Ikeja, Kaduna, Illorin, Ondo and Kano) representing different climates, to predict the date of onset and cessation of rains. The point of onset corresponds to the time when cumulative rainfall reaches $7-8 \%$ of the annual total rainfall, whereas that of rainfall cessation corresponds to $90 \%$.

${ }^{14}$ We left to Supplementary material online the detailed explanation of our interpolation method.

${ }^{15}$ Note that the anthropometric measures of these children might have either been measured or recorded with error which would bias our estimates. However, it is very unlikely that these measurement errors are related to the realization of weather in a particular place and time. 
$0-35$ months of age

$$
\begin{aligned}
\mathrm{WHZ}_{i j t}= & \alpha+\beta\left(R_{j t-1}-\overline{R_{j}}\right)+\varphi\left(R_{j t}-\overline{R_{j}}\right)+\eta \overline{R_{j}}+\xi \mathbf{X}_{i j}+\gamma_{j}+\delta_{t} \\
& +\epsilon_{i j t},
\end{aligned}
$$

where $\mathrm{WHZ}_{i j t}$ is the $\mathrm{WHZ}$-score for child $i$ in cluster $j$ at time period $t$. Note that each child in the sample is measured only once. Thus, the subscript $t$ does not imply that we have repeated observations for the same child; it only indicates the survey round and season in which the child was measured. The variables of interest are the deviations of rainfall from the long-term average during the past completed rainy season, $R_{j t-1}-\overline{R_{j}}$, and the current season rainfall shock, $R_{j t}-\bar{R}_{j}{ }^{16}$ The remaining terms are controls for total normal rainfall in cluster $j\left(\overline{R_{j}}\right)$, child observed characteristics $\left(\mathrm{X}_{i j}\right)$ such as gender and dummies for age and month of birth and fixed effects: for the month of interview and the year of interview $\left(\delta_{t}\right)$, and for state, district or cluster $\left(\gamma_{j}\right)$.

The inclusion of both shocks should allow us to separate the channels through which weather affects child health, i.e., the income and disease environment channels. In a rural setting, rainfall realisations are critical for a successful crop production. A good harvest will increase incomes and the stocks of food for the year to come, positively impacting on children's nutritional intakes and their weight. It follows that it is the realisation of rains during the last rainy season what should matter the most for current consumption. In addition, higher than normal rains during the last season might have been more conductive for the spread of disease, $E_{t-1}$, negatively affecting the child's current health status via $H_{t-1}$. Therefore, the coefficient $\beta$ cannot be signed $a$ priori since it is the net effect of two opposing forces. To the extent that the positive income effect is greater than the short-lived negative effect of the disease environment, we expected that $\beta>0$. In addition, we include the square of the past rainfall deviation to examine how rainfall variability may affect weight-for-height. While higher than usual rains should have a positive effect on income, we expect that excessive rainfall may both be harmful to crops and increase diseases.

For children surveyed during the rainy season, we also examine the impact of the current rainfall deviation, $R_{j t}-\overline{R_{j}}$ on WHZ-scores, summarised by the coefficient $\varphi$. It is expected that $\varphi<0$ since higher than normal precipitation is likely to only increase the incidence of water-borne diseases since the benefits from higher rains on crop yields and incomes have yet to be realised.

16 All rainfall values are in logs. Hence the variables on interest, which are differences of logs, should be interpreted as the percentage deviations from normal rainfall. 
Table 2: Descriptive Statistics for Weather Deviations

\begin{tabular}{|c|c|c|c|}
\hline & North & Central & South \\
\hline \multicolumn{4}{|l|}{ Height-for-age } \\
\hline \multicolumn{4}{|l|}{$\Delta R_{1}$} \\
\hline Mean & 6.23 & 3.32 & 9.49 \\
\hline Standard deviations & 12.94 & 9.66 & 9.71 \\
\hline Min & -39.56 & -92.96 & -69.35 \\
\hline Max & 45.30 & 28.57 & 22.86 \\
\hline \multicolumn{4}{|l|}{$\Delta R_{2}$} \\
\hline Mean & 2.84 & 5.00 & 11.74 \\
\hline Standard deviations & 13.73 & 9.51 & 8.01 \\
\hline Min & -39.21 & -92.96 & -47.28 \\
\hline $\operatorname{Max}$ & 45.30 & 28.57 & 22.21 \\
\hline \multicolumn{4}{|l|}{$\Delta R_{3}$} \\
\hline Mean & 4.23 & 6.02 & 11.96 \\
\hline Standard deviations & 12.88 & 12.08 & 4.77 \\
\hline Min & -39.21 & -92.96 & 0.12 \\
\hline Max & 45.30 & 28.57 & 19.93 \\
\hline \multicolumn{4}{|l|}{ Weight-for-height } \\
\hline \multicolumn{4}{|l|}{$\Delta R_{t-1}$} \\
\hline Mean & 0.24 & 2.84 & 8.49 \\
\hline Standard deviations & 12.39 & 15.77 & 8.52 \\
\hline Min & -46.06 & -69.34 & -17.43 \\
\hline Max & 53.30 & 45.47 & 18.06 \\
\hline \multicolumn{4}{|l|}{$\Delta R_{t}$} \\
\hline Mean & 7.482 & 3.03 & 5.72 \\
\hline Standard deviations & 19.95 & 14.47 & 13.80 \\
\hline Min & -32.93 & -89.65 & -43.01 \\
\hline Max & 71.27 & 77.39 & 75.32 \\
\hline
\end{tabular}

Notes: Variables are percentage deviations from normal rainfall based on interpolated values for the 2003 and 2008 DHS rural clusters.

\subsection{Height-for-age}

We also use the pooled child-level DHS sample to examine the effect of weather shocks on height-for-age; an indicator of long-term health status. There are two important differences in the relationship between rainfall shocks and height-for-age from the one described in the previous section. First, there is no point in correlating contemporaneous rainfall shocks with current height-for-age, as it is likely to respond with a lag. For this reason, one can only correlate the rainfall shocks experienced in the last or earlier completed rainfall seasons. Second, older children have experienced more than one completed rainfall season, which implies that one needs to 
take into account all the rainfall shocks experienced throughout his/her life depending on his/her age. For these two reasons, we restrict our analysis to children between 0 and 35 months of age, and group children into three cohorts depending on their age and the number of rainy seasons experienced until the time of the survey. The first group-or cohort-is composed of children younger than 12 months of age which have experienced only one completed rainy season since birth. Children in the second and third cohorts have experienced two or at most three rainy seasons by the time they were interviewed. The censoring in the relevant variables generated by this approach is accounted for by interacting the weather shock variables with dummies for each cohort. Specifically, the estimated reduced form equation is

$$
\begin{aligned}
\mathrm{HAZ}_{i j t}= & \alpha+\beta_{-1}\left(R_{j t-1}-\overline{R_{j}}\right)+\beta_{-2}\left(R_{j t-2}-\overline{R_{j}}\right) \times Y_{2,3} \\
& +\beta_{-3}\left(R_{j t-3}-\overline{R_{j}}\right) \times Y_{3}+\eta \overline{R_{j}}+\xi \mathbf{X}_{i j}+\gamma_{j}+\delta_{t}+\epsilon_{i j t},
\end{aligned}
$$

where $\mathrm{HAZ}_{i j t}$ is the HAZ-score for child $i$ in cluster $j$ measured at time period $t, Y_{2,3}$ is a binary variable identifying children who have experienced two or three rainy seasons and $Y_{3}$ is a binary variable identifying children who have experienced three completed rainy seasons. As before, the subscript $t$ only indicates the survey round in which the child was measured. As in the case of WHZ, the variables $R_{j, t-k}-\overline{R_{j}}$ represent the percentage deviation of rainfall in season $k$ (with $k=1,2,3$ ) with respect to the long-term average for cluster $j$ taking into account the length of the respective growing season (which as before varies according to the geographic location of the cluster). However, in this case the variables refer to the entire history of completed rainy seasons experienced by a child since birth. ${ }^{17}$ The additional variables included as controls in the regression are the log of normal rainfall $\left(\overline{R_{j}}\right)$, dummies for month and year of interview $\left(\delta_{t}\right)$, fixed effects by district or cluster $\left(\gamma_{j}\right)$ and a vector of children characteristics $\left(\mathbf{X}_{i j}\right)$.

As mentioned earlier, in the case of height-for-age the sign of the coefficients on the past weather shocks $\left(R_{j, t-k}-\overline{R_{j}}\right)$ cannot be determined a priori because the impact of these shocks on either consumption or health take time to materialise, making it impossible to isolate each channel. However, the effects should operate in opposite directions. Thus, a positive coefficient would be indicative of an income effect stronger than the disease environment effect, and vice versa.

17 Specifically, $R_{j t-1}$ represents total rainfall during the most recently completed rainy season, $R_{j t-2}$ represents the total rainfall two rainy seasons ago, experienced only by both 2 - and 3 -year-old children and $R_{j t-3}$ represents the total rainfall three rainy seasons ago, experienced only by 3 -year-old children. 
An implicit assumption in the specification of Equation (3) is that rainfall shocks have the same impact for each cohort, i.e., $\beta$ s are the same across cohort. By allowing the impacts of rainfall shocks to vary by cohort, we can also determine whether the impacts of shocks are transitory or not. For this purpose, we also estimate the following equation:

$$
\begin{aligned}
\mathrm{HAZ}_{i j t}= & \alpha+\sum_{c=1}^{3} \beta_{-1}^{c}\left(R_{j t-1}-\overline{R_{j}}\right)+\sum_{c=2}^{3} \beta_{-2}^{c}\left(R_{j t-2}-\overline{R_{j}}\right) \times Y_{2,3} \\
& +\beta_{-3}^{3}\left(R_{j t-3}-\overline{R_{j}}\right) \times Y_{3}+\eta \overline{R_{j}}+\xi \mathbf{X}_{i j}+\gamma_{j}+\delta_{t}+\epsilon_{i j t} .
\end{aligned}
$$

One advantage of this specification is that allows us to test whether rainfall shocks are short-lived or if they have long-lasting effects on child health. A shock may be considered as 'transitory' if the current HAZ score is significantly correlated with the rainfall shock that took place during the most recent rainy season (i.e., $\beta_{-1}^{1}$ for cohort $1, \beta_{-1}^{2}$ for cohort 2 or $\beta_{-1}^{3}$ for cohort 3 ). On the contrary, a rainfall shock may be considered as having a 'longer-lasting' impact if rainfall shocks that occurred two or three rainy seasons ago are significantly correlated with the current HAZ score of a child, i.e., if any of the coefficients $\beta_{-2}^{2}, \beta_{-2}^{3}$ and $\beta_{-3}^{3}$ is significantly different from zero.

\section{Results}

\subsection{Weight-for-height}

The least square estimates of Equation (2) with robust standard errors in the presence of intra-cluster correlation are reported in Table 3 . The sample consists of 9,931 children at the age of $0-35$ months, living and born in rural areas. The first specification includes the linear effects of current and past rainfall deviations from normals $\left(\Delta R_{t}\right.$ and $\left.\Delta R_{t-1}\right)$ and two controls: the gender of the child and the long-term average level of rainfall at the DHS cluster. In columns (2) and (3), we include the full set of controls: age in months, month of birth, month $\times$ year of interview and state-fixed effects. Column (4) of Table 3 allows for non-linear effects of current and past rainfall shocks.

The results reveal that current shocks have a negative effect on WHZ scores of young children, providing evidence of the importance of the disease environment channel in the short-run. The magnitude of the effect is also considerable. As columns (2) and (3) suggest, a 10\% positive deviation of rainfall in the current season from the long-term average reduces the WHZ score by 
Table 3: Impact of Rainfall Shocks on WHZ Scores

\begin{tabular}{llrrrr}
\hline & (1) & (2) & (3) & (4) & (5) \\
\hline$\Delta R_{t-1}$ & $0.00159(0.00227)$ & $0.00259(0.00261)$ & $0.00457(0.00291)$ & $0.00873^{1}(0.00283)$ & $0.00865^{1}(0.00311)$ \\
$\Delta R_{t}$ & $-0.00489^{1}(0.00155)$ & $-0.00360^{2}(0.00142)$ & $-0.00339^{2}(0.00148)$ & $-0.00256^{2}(0.00123)$ & $-0.00339^{1}(0.00127)$ \\
$\left(\Delta R_{t-1}\right)^{2}$ & & & $9.96 \mathrm{e}-05(6.07 \mathrm{e}-05)$ & $0.000123^{2}(0.0001)$ \\
$\left(\Delta R_{t}\right)^{2}$ & & & $8.84 \mathrm{e}-05^{1}(2.04 \mathrm{e}-05)$ & $9.36 \mathrm{e}-05^{1}(0.00002)$ \\
Health centre & & & & $0.0945^{2}(0.0461)$ \\
Health centre $\times \Delta R_{t-1}$ & & & & $0.00151(0.00328)$ \\
Health centre $\times \Delta R_{t}$ & & & & $0.00228(0.0021)$ \\
$\bar{R}$ & $0.440^{1}(0.0542)$ & $0.508(0.325)$ & $0.622^{3}(0.327)$ & $0.686^{2}(0.286)$ & $0.734^{1}(0.27)$ \\
Female & $0.0402(0.0382)$ & $0.0361(0.0374)$ & $0.0351(0.0374)$ & $0.0390(0.0372)$ & $0.0386(0.0371)$ \\
$R^{2}$ & 0.021 & 0.076 & 0.072 & 0.079 & 0.08 \\
Age FE & No & Yes & Yes & yes & Yes \\
Month of birth FE & No & Yes & Yes & Yes & Yes \\
Month interview $\times$ Year FE & No & Yes & No & Yes & Yes \\
Season interview $\times$ Year FE & No & No & Yes & Yes & No \\
State FE & No & Yes & Yes & Yes \\
\hline
\end{tabular}

Notes: The dependent variable is the WHZ-score. $\Delta R_{t}$ is the current agricultural season rainfall shock and $\Delta R_{t-1}$ is the previous season shock. The sample has 9,931 children aged $0-35$ months in rural areas. (Robust standard errors clustered by village).

${ }^{1}$ Significant at $1 \%$.

${ }^{2}$ Significant at $5 \%$.

${ }^{3}$ Significant at $10 \%$. 
0.034 to 0.036 standard deviations, on average, i.e., $17 \%$ of the median Z-score in our sample. Moreover, the inclusion of the full set of controls implies that these results are robust to individual invariant effects and statefixed effects. ${ }^{18}$

Rainfall in the last completed rainy season before the survey $\left(\Delta R_{t-1}\right)$ has a positive and significant impact on child health, but only in the last two specifications, when the square terms are introduced. This suggests that the positive income effect of higher rains during the last agricultural season is larger than the negative effect, i.e., the expansion of water-born and other diseases during that time. Thus, a $10 \%$ increase in rainfall in the last completed rainy season before the survey leads to an increase in the WHZ-score by 0.087 standard deviations (estimate from column 4 in Table 3 ). While the quadratic term on the past rainfall suggests a linear relationship with child health, the square of current rainfall indicates the presence of non-linearities. However, the magnitude of the coefficient is too small for it to have a noticeable impact.

The last column in Table 3 includes the interaction of the weather shock with households' accessibility to health facilities. For this purpose, we construct a dummy variable that captures how easy is for a woman to access a health clinic in the case of need for medical treatment. ${ }^{19}$ The results show that having relatively easy access to a medical facility significantly increases children WHZ scores. The positive coefficient of the interaction of the current shock with clinic (health centre $\times \Delta R_{t}$ ) implies that the presence of the clinic helps reduce the impact of the shock on the WHZ. In addition, the positive coefficient of the interaction with the last season rainfall shock implies that the presence of the clinic reinforces the net effect of the income and disease environment effect, probably due to the reduction of the environment disease subcomponent. Although the coefficients on the interactions have meaningful interpretations, their signs are not statistically significant.

${ }^{18}$ We also test whether the estimated impacts are due to negative or positive shocks, or a combination of both. In unreported specifications, we estimate the model for negative and positive shocks alone, setting to zero the other type of shock and including dummy variables for the censoring. The results suggest that the negative impact of current shocks is due to the positive deviation rather than negative ones. This means that higher than normal precipitation is responsible for the observed negative impact on WHZ scores. This result seems very plausible since excessive rains are associated with the spread of vector-borne diseases.

19 The DHS provides valuable information about access to medical facilities and medical treatments. In particular, women respond that distance to a health facility is either 'not a big problem' or 'a big problem' when seeking medical treatment. 
Two remaining questions are whether these impacts differ across boys and girls, and across age groups. We first examine differences across ages in the impact of precipitation on weight-for-height (results not reported). The effect of the past rainfall is significant across ages and it is of similar magnitude. In contrast, the effect of current rainfall shocks is significant for 1- and 2 -year-old children, but not for the older children. As previously mentioned, the income effect may be stronger for girls than for boys if girls are discriminated in favour of boys in times of economic hardship. However, our results do not support this claim. Boys seem to benefit to a greater extent by past rainfall shocks, girls seem to do worse than boys when diseases are more likely, i.e., when the current rainfall is higher than normal. However, most of the coefficients across age groups are not significantly different from zero.

The adverse effect of the current rainfall on weight-for-height seems to be caused by the disease environment. To further explore this issue, we analysed the effect that current rainfall shocks have on the likelihood of reporting diarrhoea in the last 2 weeks prior to the interview. ${ }^{20}$ Diarrhoea is a particularly important disease to study in this context because of its sensitivity to climatic conditions. Higher than normal rains significantly affect the incidence of diarrhoea (results not reported). The magnitude of the effect is larger for 2 and 3 year old, but the coefficient is significant only for the former. This result is in line with Keusch et al. (2006) reporting that the prevalence of diarrhoea peaks among infants and young children (those between 6 and 12 months of age). Lastly, we also find that the coefficient of the last season rainfall does not affect the incidence of diarrhoea at the time of survey.

\subsection{Height-for-age}

The significant impact that rainfall during the last season has on weight-for-height indicates that shocks might have a medium-run effect on child health. For further evidence we now turn our attention to the effect that rainfall shocks during previous seasons have on the HAZ-scores, which as opposed to weight-for-height should better capture chronic nutritional status.

Table 4 presents the results for different specifications of Equation (3) on a sample of 10,728 children in rural areas. As mentioned in the previous section, we focus on completed rainy seasons since a child was born. For

${ }^{20}$ The incidence of diarrhoea for children surveyed during the rainy season is $11 \%$ for the two rounds combined. However, diarrhoea was more likely (about 15\%) among children surveyed in the (smaller) 2003 round. 
Table 4: Impact of Rainfall Shocks on HAZ Scores

\begin{tabular}{|c|c|c|c|c|c|c|}
\hline & (1) & (2) & (3) & (4) & (5) & (6) \\
\hline$\Delta R_{1}$ & $\begin{array}{l}0.00403 \\
\quad(0.00306)\end{array}$ & $\begin{array}{l}0.00330 \\
(0.00300)\end{array}$ & $\begin{array}{l}0.00560^{1} \\
(0.00277)\end{array}$ & $\begin{array}{l}0.00601^{1} \\
\quad(0.00279)\end{array}$ & $\begin{array}{l}0.00672^{1} \\
\quad(0.00305)\end{array}$ & $\begin{array}{l}0.00707^{1} \\
(0.00301)\end{array}$ \\
\hline$\Delta R_{2}$ & $\begin{array}{l}0.0114^{2} \\
\quad(0.00401)\end{array}$ & $\begin{array}{l}0.0119^{2} \\
\quad(0.00402)\end{array}$ & $\begin{array}{l}0.0119^{2} \\
(0.00395)\end{array}$ & $\begin{array}{l}0.0122^{2} \\
\quad(0.00398)\end{array}$ & $\begin{array}{l}0.0126^{2} \\
(0.00433)\end{array}$ & $\begin{array}{l}0.0123^{2} \\
(0.00440)\end{array}$ \\
\hline$\Delta R_{3}$ & $\begin{array}{r}-0.00727 \\
(0.0126)\end{array}$ & $\begin{array}{l}0.00329 \\
(0.0131)\end{array}$ & $\begin{array}{l}0.00500 \\
(0.0134)\end{array}$ & $\begin{array}{l}0.00541 \\
(0.0133)\end{array}$ & $\begin{array}{l}0.00528 \\
(0.0149)\end{array}$ & $\begin{array}{l}0.00362 \\
(0.0148)\end{array}$ \\
\hline$\left(\Delta R_{1}\right)^{2}$ & & & & & & $\begin{array}{l}-2.24 \mathrm{e}-05 \\
(0.000184)\end{array}$ \\
\hline$\left(\Delta R_{2}\right)^{2}$ & & & & & & $\begin{array}{r}-0.000105 \\
(0.000235)\end{array}$ \\
\hline$\left(\Delta R_{3}\right)^{2}$ & & & & & & $\begin{array}{l}0.000454 \\
(0.000773)\end{array}$ \\
\hline$\Delta T_{1}$ & & & & & $\begin{array}{r}-0.0663^{1} \\
(0.0308)\end{array}$ & $\begin{array}{r}-0.0675^{1} \\
(0.0308)\end{array}$ \\
\hline$\Delta T_{2}$ & & & & & $\begin{array}{r}-0.0829^{3} \\
(0.0453)\end{array}$ & $\begin{array}{r}-0.0816^{3} \\
(0.0481)\end{array}$ \\
\hline$\Delta T_{3}$ & & & & & $-0.111(0.132)$ & $\begin{array}{r}-0.0908 \\
(0.142)\end{array}$ \\
\hline $\bar{R}$ & $0.525^{2}(0.0612)$ & $0.471^{2}(0.0607)$ & $-0.457(0.415)$ & $-0.526(0.408)$ & $-0.637(0.416)$ & $-0.665(0.414)$ \\
\hline Female & $0.245^{2}(0.0428)$ & $0.252^{2}(0.0428)$ & $0.264^{2}(0.0425)$ & $0.264^{2}(0.0425)$ & $0.267^{2}(0.0425)$ & $0.267^{2}(0.0424)$ \\
\hline$R^{2}$ & 0.07 & 0.09 & 0.11 & 0.11 & 0.11 & 0.11 \\
\hline Age FE & No & Yes & Yes & Yes & Yes & Yes \\
\hline Month of birth FE & No & Yes & Yes & Yes & Yes & Yes \\
\hline $\begin{array}{l}\text { Month interview } \times \text { year } \\
\text { FE }\end{array}$ & No & Yes & Yes & No & Yes & Yes \\
\hline
\end{tabular}


Table 4: Continued

\begin{tabular}{lllllll}
\hline & $(\mathbf{1})$ & (2) & (3) & (4) & (5) & (6) \\
\hline $\begin{array}{l}\text { Season interview } \times \text { year } \\
\text { FE }\end{array}$ & No & No & No & Yes & No & No \\
State FE & No & No & Yes & Yes & Yes & Yes \\
\hline
\end{tabular}

Notes: The dependent variable is the $\mathrm{HAZ}$-score. $\Delta R_{1}$ is the last agricultural season rainfall shock and $\Delta R_{2}$ is the rainfall shock the season before last. The sample has 10,728 children aged $0-35$ months in rural areas. (Robust standard errors clustered by village).

${ }^{1}$ Significant at $5 \%$.

${ }^{2}$ Significant at $1 \%$.

${ }^{3}$ Significant at $10 \%$. 
instance, $\Delta R_{1}$ is the deviation of rainfall during the first completed growing season experienced by a child, and $\Delta R_{2}$ and $\Delta R_{3}$ are the second and third seasons, respectively. In the first four columns, we include the deviation from normal rainfall, each with a different set of controls. ${ }^{21}$ In general, the estimated regressions show that rainfall shocks at early life have a significant effect on the HAZ scores. Moreover, the positive coefficients suggest that the benefits through the income channel more than compensate any negative impact that higher rainfall may have on child health due to the expansion of water-borne and other diseases.

As opposed to the WHZ case, we are now able to control for the corresponding temperature shocks. ${ }^{22}$ Note that while rainfall shocks have an ambiguous effect on child health (depending on the relative strength of the income and disease environment channels), temperature shocks always have a negative impact on child health, especially in certain temperate locations. Higher temperatures increase the incidence of diseases and also reduce agricultural yields, lowering the subsequent nutritional intakes. We present the results in column (5). In line with our reasoning, we find that temperature shocks at early life have a negative impact on HAZ-scores. In addition, the coefficients on rainfall deviations are still negative and significant, and the inclusion of temperature shocks does not affect their magnitudes.

Lastly, we test for non-linearities by including the square of weather shocks. As we already mentioned, if rainfall shocks affect child health linearly, then any increase in the variance of rainfall (for example, induced by climate change) might not have any additional impact on the expected health outcome. In contrast, if a quadratic relationship exists between shocks and health, then any change in its variance will also affect the mean health outcome. Results presented in column (6) show that the square coefficients are not statistically significant implying that rainfall affects health linearly. ${ }^{23}$

${ }^{21}$ Controls include fixed effects by age, month of birth, month $\times$ year of interview, season $\times$ year of interview and state.

22 Unfortunately, the quality of the temperature records for 2008, the year of the last and larger DHS survey, is not reliable enough, and hence we decided to exclude temperature from the $\mathrm{WHZ}$ regressions. In the case of HAZ, the last completed growing season for the vast majority of the sample is 2007.

${ }^{23}$ We also test whether the estimated impacts are mainly driven by negative or positive shocks. For these, we first set to zero the positive rainfall shocks and control for the censoring by including a dummy variable. We then re-estimate the model using the same procedure but considering this time only the positive deviations. Results (not reported) suggest that the positive effects that rainfall has on HAZ scores reported in Table 4 occurs for both negative and positive shocks. That means that reducing negative shocks has impact 
So far we have shown that past weather shocks impact child health, but we have not been able to say anything about whether these shocks have a permanent effect or not. In other words, saying that shocks in the first and second seasons of life have an impact on child health is not enough to say that they have a long-lasting impact because they might affect the younger children but not the oldest. To analyse this issue, we group children into cohorts according to the number of completed rainy season that they have experienced since birth, and then interact each cohort with the rainfall deviations in different time periods as explained by Equation (4). Examining exogenous shocks in several periods at early life for each cohort allow us to identify the most critical periods, and ultimately to understand the persistency of their impacts. Results presented in columns 1 and 2 of Table 5 suggest that weather shocks (both rainfall and temperature) are transitory, since it is only the last season shock that matters for HAZ scores $\left(\Delta R_{1}\right.$ and $\Delta T_{1}$ for the first cohort and $\Delta R_{2}$ and $\Delta T_{2}$ for the second cohort). In the last two columns, we split the sample between boys and girls to see if there is any difference across gender groups. Again, results are indicative of similar-in magnitude — transitory impacts of weather shocks for both groups.

The short-lived nature of past weather shocks seem to indicate that children who have experienced a shock can rapidly catch-up with their nigerian cohort. Our findings are in line with some results reported in the epidemiologic literature, but seem to contradict Maccini and Yang (2009) who report that shocks during the first 12 months since birth have an effect on socioeconomic outcomes of Indonesian women as adults.

\section{Conclusions}

In this study, we have investigated the extent to which rainfall shocks affect the welfare of children in rural Nigeria. Understanding the socioeconomic consequences of rainfall variability is a prerequisite for the integration of adaptation activities into poverty reduction efforts. This is especially relevant in the context of global climate change and the projected increase of weather variability.

Among the key findings of this study is that rainfall shocks have a significant impact on child health irrespective of the dimension of child welfare examined in rural Nigeria. In addition, it appears that the impacts of these shocks are the same for young boys and girls, which suggests that there is

on HAZ scores similar to that of increasing a positive shock by the same magnitude, though results are more robust when considering the positive deviations. 
Table 5: Impact of Rainfall Shocks on HAZ Scores by Cohort

\begin{tabular}{|c|c|c|c|c|}
\hline & (1) & (2) & (3) & (4) \\
\hline cohort0 $-11 \times \Delta R_{1}$ & $0.0157^{1}(0.00385)$ & $0.0198^{1}(0.00467)$ & $0.0208^{1}(0.00552)$ & $0.0187^{1}(0.00655)$ \\
\hline cohort12 $-23 \times \Delta R_{1}$ & $-0.00490(0.00443)$ & $-0.00222(0.00452)$ & $-0.00333(0.00601)$ & $-0.00122(0.00584)$ \\
\hline cohort12 - $23 \times \Delta R_{2}$ & $0.0163^{1}(0.00459)$ & $0.0221^{1}(0.00529)$ & $0.0189^{2}(0.00742)$ & $0.0254^{1}(0.00680)$ \\
\hline cohort24 - $35 \times \Delta R_{1}$ & $-0.0176(0.0123)$ & $-0.0108(0.0142)$ & $-0.0166(0.0166)$ & $-0.0113(0.0226)$ \\
\hline cohort24 - $35 \times \Delta R_{2}$ & $0.00582(0.00810)$ & $0.0138(0.00979)$ & $-0.00117(0.0118)$ & $0.0242(0.0151)$ \\
\hline cohort24 - $35 \times \Delta R_{3}$ & $0.00774(0.0139)$ & $0.00662(0.0181)$ & $0.0400(0.0250)$ & $-0.0197(0.0264)$ \\
\hline cohort12 $-23 \times \Delta T_{1}$ & & $0.0168(0.0409)$ & $0.0297(0.0570)$ & $0.0111(0.0540)$ \\
\hline cohort12 - $23 \times \Delta T_{2}$ & & $-0.148^{1}(0.0512)$ & $-0.147^{2}(0.0681)$ & $-0.159^{2}(0.0692)$ \\
\hline cohort24 - $35 \times \Delta T_{1}$ & & $0.393(0.410)$ & $0.0163(0.504)$ & $0.674(0.683)$ \\
\hline cohort24 - $35 \times \Delta T_{2}$ & & $0.0719(0.123)$ & $0.177(0.155)$ & $0.0500(0.217)$ \\
\hline cohort24 - $35 \times \Delta T_{3}$ & & $0.0484(0.204)$ & $-0.220(0.259)$ & $0.310(0.329)$ \\
\hline $\bar{R}$ & $-0.392(0.410)$ & $-0.676(0.418)$ & $-0.961^{2}(0.486)$ & $-0.374(0.491)$ \\
\hline Female & $0.263^{1}(0.0424)$ & $0.265^{1}(0.0426)$ & & \\
\hline Age FE & Yes & Yes & Yes & Yes \\
\hline Month of birth FE & Yes & Yes & Yes & Yes \\
\hline Month interview $\times$ Year FE & Yes & Yes & Yes & Yes \\
\hline State FE & Yes & Yes & Yes & Yes \\
\hline
\end{tabular}

Notes: The dependent variable is the HAZ-score. $\Delta R_{1}$ is the last agricultural season rainfall shock and $\Delta R_{2}$ is the rainfall shock the season before last. Specification (3) only boys and (4) only girls. The sample has 10,728 children aged $0-35$ months in rural areas. (Robust standard errors clustered by village).

${ }^{1}$ Significant at $1 \%$.

${ }^{2}$ Significant at $5 \%$. 
no discrimination in the allocation of household resources. The negative impact of contemporaneous rainfall shocks on child weight-for-height reveals the importance of the disease environment in determining health status in the short-run. This finding is reinforced by the positive and significant effect that rainfall shocks have on the incidence of diarrhoea among children. Taking into consideration the fact that diarrhoea is the leading cause of child malnutrition, and the second leading cause of death for young children, ${ }^{24}$ our findings suggest that there is an ample room for policy intervention in this area. Low-cost public health interventions-like oral rehydration therapy - will certainly reduce the negative impacts that weather shocks have on short-term child malnutrition. In this sense, one of the contributions of this study was to show that having easy access to a health clinic significantly improves children's weight-for-height. We also find some evidence, albeit weak, on the important mitigating effect that health interventions may have on child health after experiencing a weather shock.

It is also the case that above normal precipitation during the last completed rainy season has a positive impact on child weight-for-height, which suggests that the income effect associated with a higher than normal rainfall during the previous agricultural cycle is stronger than the negative effect of the disease environment. The importance of the income effect-operating mainly through the positive effects of higher than normal rainfall on agricultural production - suggests that advances in weather prediction and monitoring techniques can be employed to develop early warning systems to alert rural communities as a means of reducing the risks of crop failure.

Rainfall shocks also appear to have an effect on a long-term measure of children nutritional status such as height-for-age. As in the case for weight-for-height, rainfall shocks during the most recent rainy season have a positive effect on the HAZ score, suggesting an income effect stronger than the disease environment effect. However, the fact that it is only the shock from the last completed rainfall season, and not the shocks from earlier seasons, those that have a significant effect across different ages, implies that children are able to catch-up with their nigerian cohort soon after the occurrence of a shock.

\section{Supplementary material}

Supplementary material available at JAFECO online.

24 According to the World Health Organization (2002), in developing countries children under 3-year-old experience on average three episodes of diarrhoea every year, with each episode depriving children of the nutrition necessary for growth. 


\section{Funding}

This study was financed in part by the Trust Fund for Environmental and Socially Sustainable Development (TFESSD) of the World Bank.

\section{References}

Alderman, H., J. Hoddinott and B. Kinsey (2006) 'Long Term Consequences of Early Childhood Malnutrition', Oxford Economic Papers, 58: 450-74.

Baird, S., J. Friedman and M. Smitz (2010) 'Climate Variability and Infant Mortality in Africa', Unpublished manuscript. Washington, DC: The World Bank.

Bandyopadhyay, S., S. Kanji and L. Wang (2012) 'The Impact of Rainfall and Temperature Variation on Diarrheal Prevalence in Sub-Saharan Africa', Applied Geography, 33: 63-72.

Behrman, J. and A. Deolalikar (1988) 'Health and Nutrition', in H. Chenery and T. N. Srinivasan (ed.), Handbook of Development Economics. Amsterdam: Elsevier.

Behrman, J. and A. Deolalikar (1990) 'The Intrahousehold Demand for Nutrients in Rural South India: Individual Estimates, Fixed Effects, and Permanent Income', Journal of Human Resources, 25 (4): 665-96.

Bengtsson, N. (2010) 'How Responsive is Body Weight to Transitory Income Changes? Evidence from Rural Tanzania', Journal of Development Economics, 92: $53-61$.

Confalonieri, U., B. Menne, R. Akhtar, K. L. Ebi, M. Hauengue, R. S. Kovats, B. RevichA. Woodward (2007) 'Human Health. Climate Change 2007: Impacts, Adaptation and Vulnerability', in M. L. Parry, O. F. Canziani, J. P. Palutikof, P. J. van der Linden and C. E. Hanson (eds.), Contribution of Working Group II to the Fourth Assessment Report of the Intergovernmental Panel on Climate Change. Cambridge, UK: Cambridge University Press, pp. 391-431.

Currie, J. (2009) 'Healthy, Wealthy and Wise: Socioeconomic Status, Poor Health in Childhood and Human Capital Development', Journal of Economic Literature, 47 (1): $87-122$.

Dercon, S. (2002) 'Income Risk, Coping Strategies, and Safety Nets', The World Bank Research Observer, 17 (2): 141-66.

Dercon, S. and C. Porter (2010) 'Live Aid Revisited: Long-term Impacts of the 1984 Ethiopian Famine on Children', Unpublished manuscript, Centre for the Study of African Economies WPS/2010-39.

Dreze, J. and A. Sen (1989) 'Hunger and Public Action', WIDER Studies in Development Economics. Oxford: Oxford University Press.

Falkner, F. and J. M. Tanner (1986) Human Growth: A Comprehensive Treatise, vol. 3. New York: Plenum.

Foster, A. (1995) 'Prices, Credit Markets and Child Growth in Low-Income Rural Areas', Economic Journal, Royal Economic Society, 105 (430): 551-70. 
Glewwe, P. and E. Miguel (2008) 'The Impact of Child Health and Nutrition on Education in Less Developed Countries', Handbook of Development Economics, 4: 3561-606.

Hoddinott, J. and B. Kinsey (2001) 'Child Growth in the Time of Drought', Oxford Bulletin of Economics and Statistics, 63 (4): 409-36.

ICF Macro. (2011) Incorporating Geographic Information into Demographic and Health Surveys: A Field Guide to GPS Data Collection. Maryland, USA: ICF Macro. Jacoby, H. and E. Skoufias (1997) 'Risk, Financial Markets, and Human Capital in a Developing Country', Review of Economic Studies, 64 (3): 311-35.

Jensen, R. (2000) 'Agricultural Volatility and Investment in Children', American Economic Review, 90 (2): 399-404.

Keusch, G. T., O. Fontaine, A. Bhargava, C. Boschi-Pinto, Z. Bhutta and E. Gotuzzo (2006) 'Diarrheal Diseases', in D. T. Jamison, J. G. Breman, A. R. Measham, G. Alleyne, M. Claeson, D. B. Evans, P. Jha, A. Mills and P. Musgrove (eds), Disease Control Priorities in Developing Countries, 2nd edn. New York: Oxford University Press.

Kudamatsu, M., T. Persson and D. Strömberg (2012) 'Weather and Infant Mortality in Africa', Sweden: Stockholm University.

Maccini, S. and D. Yang (2009) 'Under the Weather: Health, Schooling, and Economic Consequences of Early-life Rainfall', American Economic Review, 99 (3): 1006-26.

Martorell, R., L. Kettel Khan and D. Schroeder (1994) 'Reversibility of Stunting: Epidemiological Findings in Children from Developing Countries', European Journal of Clinical Nutrition, 48: 45-57.

Mei, Z. and L. M. Grummer-Strawn (2007) 'Standard Deviation of Anthropometric Z-scores as a Data Quality Assessment Tool Using the 2006 WHO Growth Standards: A Cross Country Analysis', Bulletin of the World Health Organization, 85 (6): $441-8$.

Nordhaus, W., R. Mendelsohn and D. Shaw (1994) 'The Impact of Global Warming on Agriculture: A Ricardian Approach', American Economic Review, 84 (4): $753-71$.

Odekunle, T. O. (2004) 'Rainfall and the Length of the Growing Season in Nigeria', International Journal of Climatology, 24: 467-79.

Portner, C. (2010) 'Natural Hazards and Child Health', Working Paper UWEC-201003, University of Washington, Department of Economics.

Rose, E. (1999) 'Consumption Smoothing and Excess Female Mortality in Rural India', Review of Economics and Statistics, 81 (1): 41-9.

Skoufias, E. and K. Vinha (2012) 'Climate Variability and Child Height in Rural Mexico', Economics \& Human Biology, 10 (1), 54-73.

Strauss, J. and D. Thomas (1998) 'Health, Nutrition, and Economic Development', Journal of Economic Literature, 36 (2): 766-817.

World Health Organization. (2002) 'Health and Environment in Sustainable Development', Technical Report Series. Geneva: WHO. 
World Health Organization Multicentre Growth Reference Study Group. (2006). WHO Child Growth Standards: Length/height-for-age, weight-for-age, weight-for-length, weight-for-height and body mass index-for-age: Methods and development. Geneva: World Health Organization, pp. 312. (http://www.who.int/ childgrowth/publications/en/).

Yang, D. and H. Choi (2007) 'Are Remittances Insurance? Evidence from Rainfall Shocks in the Philippines', World Bank Economic Review, 21 (2): 219-48. 